\title{
DEL LAICISMO AL SUFRAGISMO. MARCOS CONCEPTUALES Y ESTRATEGIAS DE ACTUACIÓN DEL FEMINISMO REPUBLICANO ENTRE LOS SIGLOS XIX Y XX*
}

\author{
Luz Sanfeliu
}

\section{La educación femenina. Difundir la injusticia, proponer soluciones}

Durante la Restauración canovista, en un sistema político falto de garantías y libertades, se prolongaron los intentos femeninos reivindicativos que ya habían tenido lugar durante el Sexenio democrático, en publicaciones como $\mathrm{La}$ Ilustración de la Mujer que se imprimió en Madrid desde 1873 bajo la dirección de Sofía Tartilán. En ella colaboraron Matilde Cherner, más conocida por el seudónimo Rafael Luna y como autora vinculada al republicanismo, o Josefa Pujol, directora de la publicación liberal El Parhtenón (1880) en la que convivían krausistas y naturalistas ${ }^{1}$. En esta publicación se recomendaba a las mujeres el cumplimiento de sus deberes familiares aun cuando su reclamación central era la mejor preparación intelectual de la población femenina. Según Geraldine Scalon los artículos publicados en la revista por Sofía Tartilán, recogidos en 1877 en el libro Páginas para la educación popular, junto a las obras de Concepción Arenal, La mujer del porvenir (1869) y La mujer de su casa (1883) supusieron en su tiempo la denuncia más clara y contundente de la educación tradicional de las mujeres². Otra escritora de renombre,

\footnotetext{
* Trabajo realizado en el marco del Proyecto I+D+I, núm. 149/05.

1. Rodríguez SÁnchez, Ma de los Ángeles, «Matilde Cherner y 'La Ilustración de la Mujer'», en DíAz LARIOS, Luis F. [et al.] (eds.), Lectora, Heroína, Autora (La mujer en la literatura española del siglo XIX). III Coloquio de la Sociedad de Literatura Española del Siglo XIX (Barcelona, 23-25 de octubre de 2002), Barcelona, 2005, pp. 307-319.

2. SCANLON, Geraldine M., La polémica feminista en la España Contemporánea (1868-1974), Madrid, 1976, pp. 22-23.
} 
Concepción Gimeno de Flaquer, próxima en esos años a las corrientes regeneracionistas finiseculares, publicó asimismo en 1877 un ensayo titulado La mujer española. Estudios acerca de su educación y de sus facultades intelectuales ${ }^{3}$. En este libro se observaba también el magisterio de Concepción Arenal puesto que ambas coincidían en afirmar que la instrucción era un derecho equiparable para ambos sexos. Se expresaban así reflexiones compartidas por los sectores femeninos que en esos años se mostraban más comprometidos con la defensa de su propio sexo, mujeres que veían en Concepción Arenal la voz más autorizada de todas ellas'.

La trayectoria intelectual de Concepción Gimeno de Flaquer se había forjado dirigiendo La Ilustración de la Mujer, publicada en Barcelona en 1872. La revista había sido auspiciada económicamente por la Sociedad de Crédito Intelectual dirigida por Nicolás Díaz de Benjumea, de tendencia política federal y relacionado con el esoterismo. Desde La Ilustración de la Mujer se vindicaba la educación física, intelectual y moral de las mujeres promoviendo el cambio de los modelos formativos conservadores. Dirigida por Gertrudis Gómez de Avellaneda desde 1882, fue la primera publicación que se hizo eco con entusiasmo de las actividades del sufragismo británico y que difundió la convocatoria del Congreso Feminista que preparaba a Junta de Señoras de la Unión Obrera Balear5.

En el camino de hacer consciente a la sociedad de lo injusto de la discriminación femenina se estaba reconstruyendo un embrionario protofeminismo hispano, escasamente investigado, que utilizaba básicamente la prensa como tribuna desde la que defender la validez intelectual de las mujeres y demandar su acceso a profesiones liberales que tradicionalmente se les había negado. Se trataba, como afirman quienes se han ocupado de analizar el proceso de construcción de los movimientos sociales, de hacer visible y explicar ante la opinión pública la situación de injusticia y desigualdad que vivían las mujeres, difundiendo nuevos marcos conceptuales sobre el significado de sus reclamaciones y proponiendo, además, posibles soluciones ${ }^{6}$.

3. Martinez, Cándida [et al.] (dir.), Mujeres en la Historia de España. Enciclopedia biográfica, Barcelona, 2000, pp. 548-551.

4. Ayala Aracil, $M^{a}$ de los Ángeles, «La mujer española, de Concepción Gimeno de Flaquer», en DíAz LARIOS, Luis F. [et al.] (eds.), Lectora, Heroína, Autora..., pp. 13-21.

5. FAGOAGA, Concha, La voz y el voto de las mujeres El sufragismo en España 1877-1931, Barcelona, 1985, pp. 74-76.

6. KLANDERMANS, Bert, «La construcción social de la protesta y los campos pluriorganizativos», en LARAÑA, Enrique y GUSFIELD, Joseph, Los nuevos movimientos sociales. De la ideología a la identidad, Madrid, 2001, pp. 195-198. 
Solidaridades interclasistas reunían a mujeres de clases medias o aristocráticas de tendencias ideológicas no siempre coincidentes que promovían un reformismo moderado en torno a la feminidad. Valga como ejemplo la participación de muchas de las escritoras de la prensa anteriormente mencionada, Sofía Tartilán, Josefa Pujol, Natividad Rojas o Concepción Gimeno Flaquer, en la obra colectiva de tintes costumbristas titulada Las mujeres españolas, americanas y lusitanas pintadas por sí mismas dirigida por Faustina Sáez de Melgar $^{7}$. A estas autoras se añadía también la colaboración en dicha obra de Patrocinio de Biedma, Rosario de Acuña, Blanca de los Ríos o Emilia Pardo Bazán a las que básicamente les unía su dedicación a la literatura y su preocupación por la llamada "cuestión femenina».

Se abría con estas publicaciones un proceso de autorreflexión, de constitución de redes y de complicidades femeninas cuyos límites acotaba en 1900 en La Revista Blanca Soledad Gustavo, quien rechazaba violentamente a Josefa Pujol, por su creencia y promoción insistente en un modelo único de mujer ${ }^{8}$. Pocos años más tarde, las diferencias de posiciones ideológicas comenzarían a levantar fronteras entre diversas concepciones de la feminidad y otros feminismos, en mayor medida organizados, tomarían el relevo difundiendo las desigualdades entre los sexos como parte no sólo de la «cuestión social», sino también de la «cuestión política».

En 1882, desde posiciones más próximas al republicanismo federal, también en Barcelona, vio la luz la revista La Muger que estuvo dirigida por Therese Coudray. La publicación se prolongó con el título de El Álbum del Bello Sexo bajo la misma dirección y posteriormente siguió en la calle hasta 1886 con el nombre de El Sacerdocio de la Mujer. Los ideales emancipadores se difundieron en sus páginas de forma en mayor medida radical ya que las demandas de derechos para las mujeres incluían el derecho al voto. Además, muchos de sus artículos estaban dedicados a la relación de la ciencia con la feminidad y a la posibilidad de que las mujeres cursaran carreras superiores ${ }^{9}$. En este caso, derechos políticos y educativos articulaban un proyecto que suponía

7. SÁEZ De Melgar, Faustina, Las mujeres españolas, americanas y lusitanas pintadas por sí mismas, Barcelona, 1882. La publicación está disponible en la Biblioteca Virtual Miguel de Cervantes.

8. Soledad Gustavo, «El anarquismo y la mujer», La Revista Blanca, nº 49, 1-VII-1900, pp. 5-9. Citado por Bussy GenEvols, Danièle, «La función de directora en los periódicos femeninos, 1862-1936 o la «sublime misión»», en DESVOIS, Jean-Michel y BOTREL, JeanFrançois (ed.), Prensa, impresos, lectura en el mundo hispánico contemporáneo. Homenaje a Jean François Botrel, Bordeaux, 2005, p. 196.

9. SEgura, Isabel y Selva, Marta, Revistes de dones, Barcelona, 1984, p. 101 y SEgura SORIANO, Isabel, Revistas de Mujeres. Calendario de 1998, Barcelona, 1998. 
también cierta acción organizativa que sobrepasaba los límites de la escritura. En relación con la revista se celebró un mitin al que acudieron 37 mujeres y es factible que la revista fuese editada por la Sociedad General de Señoras ${ }^{10}$.

En términos de oportunidad, las demandas de instrucción superior y el derecho femenino a ejercer profesiones liberales coincidían en el tiempo con las polémicas abiertas en torno a la voluntad de unas pocas mujeres matriculadas en las universidades españolas de obtener el doctorado. La polémica se resolvió cuando el gobierno negó a las mujeres el acceso a la enseñanza secundaria y superior sin autorización individual por parte de la Dirección General de Instrucción Pública. La cuestión a dilucidar era no sólo qué tipo de educación era adecuada para las mujeres, sino también si los títulos universitarios las habilitaban para ejercer las profesiones en las que habían sido formadas ${ }^{11}$. En todo caso, otra de las tareas de los nuevos y también de los «viejos» movimientos sociales consiste en llevar a término ciertas rupturas con el sistema de normas sociales, de modo que se establezcan y normalicen los modelos identitarios que proponen ${ }^{12}$.

Los consensos sociales establecidos a favor de la educación de las mujeres hicieron posible que las dificultades en los trámites no desanimaran a las mujeres que habían accedido a las universidades. En 1882, dos médicas, Dolores Aleu y Martina Castells obtuvieron el doctorado y abrieron consultas ginecológicas en Barcelona. Hasta 1900, en un ambiente con frecuencia hostil, treinta mujeres cursaron estudios superiores en España y un alto porcentaje de ellas desarrollaron efectivamente una carrera profesional ${ }^{13}$. Se comenzaban a consolidar los intentos de articular identidades femeninas más amplias, pese a que los modelos que promovían el ideal de domesticidad y la complementariedad entre los sexos continuaban vigentes, en un contexto marcado también por la falta de recursos que afectaba a los estratos más desfavorecidos de la sociedad. Las tasas de alfabetización en España por esas mismas fechas son elocuentes al respecto. Frente a un 42,1 de hombres alfabetizados sólo 25,1 de mujeres gozaban de conocimiento que les dieran acceso a la lectura y escritura ${ }^{14}$.

10. FAGOAGA, Concha, La voz y el voto de las mujeres...., pp. 65-76.

11. Flecha García, Consuelo, Las primeras universitarias en España, Madrid, 1996, pp. $100-112$.

12. Mueller, Carol, «Identidades colectivas y redes de conflicto. El origen de las movilizaciones de las mujeres en Estados Unidos, 1990-1970», en LARAÑA, Enrique y GUSFIELD, Joseph, Los nuevos movimientos sociales...., pp. 287-296.

13. FleCha GARCía, Consuelo, Las primeras universitarias en España..., pp. 190-213.

14. CAPEL, Rosa $\mathrm{M}^{a}$, El trabajo y la educación de la mujer en España (1900-1930), Madrid, 1982, pp. 362-363. 
La subversión de las normas que negaban la igualdad intelectual y profesional de los sexos iniciaba una andadura no exenta de dificultades, aunque contando también con el apoyo y la contribución paralela de los sectores vinculados a La Institución Libre de Enseñanza, que en torno a 1871 y a través de la Asociación para la Enseñanza de la Mujer, pusieron en pie diversos centros no confesionales por todo el estado español donde se preparaba a las mujeres para ejercer profesiones intermedias ${ }^{15}$. En el Congreso Pedagógico HispanoPortugués-Americano de 1892 con la participación de los institucionistas y de figuras femeninas relevantes como Concepción Arenal y Emilia Pardo Bazán, se hicieron manifiestos los tímidos cambios que se estaban operando. Valga reseñar que la participación femenina fue activa tanto en el comité organizador como en las mesas que presidían las secciones, reflejando el abanico cada vez más amplio de mujeres que ocupaban posiciones profesionales: maestras, profesoras de escuela normal, directoras de colegios privados, escritoras, médicas y estudiantes universitarias. También, en medio de una viva polémica, se recogieron los principios igualitarios en lo que hacía referencia a la enseñanza de las mujeres. Sin embargo, su ejercicio profesional sólo fue aceptado en la esfera educativa ${ }^{16}$.

Pese a la progresiva consolidación de discursos y prácticas femeninas que, aunque muy minoritarios, tendían a cierto igualitarismo en la esfera educativa o profesional, las limitaciones de las mujeres eran aún manifiestas en otros ámbitos de la participación política y social como revela la oposición de ciertos sectores sociales a que tuviera lugar el Congreso Nacional Femenino que en 1883 debía haberse celebrado en Palma ${ }^{17}$.

En este caso, la Unión Obrera Balear fundada en 1881 por los republicanos federales contaba con una Sección de Señoras integrada por mujeres pertenecientes a la sociedad obrera femenina El Auxilio Federal y por núcleos femeninos que ya habían demandado derechos y libertades para las mujeres en la etapa del Sexenio. Los objetivos de la convocatoria se cifraban en mejorar la condición de las mujeres que debían apostar por la laicidad y en hacerlas participar de una instrucción científica y racionalista. Especial atención merece el hecho de la designación de Martina Castells i Ballespí, una de

15. Di FEBO, Guliana, «Orígenes del debate feminista en España: la escuela krausista y la Institución Libre de Enseñanza (1870-1890)», Sistema, no 12 (1976), pp. 59-70.

16. CAPEl Martínez, Rosa $\mathrm{M}^{\mathrm{a}}$, «La apertura del horizonte cultural femenino: Fernando de Castro y los Congresos Pedagógicos del siglo XIX», en DurAN, $\mathrm{M}^{a}$ Ángeles [et al.] (eds.), Mujeres y sociedad en España, 1700-1975, Madrid, 1986, pp. 128-145.

17. PeÑARRUBiA, Isabel, Entre la ploma i la tribuna. Els orígens del primer feminismo a Mallorca, 1869-1890, Barcelona, 2006, pp. 175-245. 
las primeras ginecólogas que obtuvo el grado de doctorada en España, para presidir el citado Congreso. En las sesiones preparativas, la Junta de Señoras recibió a su vez duras críticas desde la intransigencia clerical cuya prensa hacía constar el peligro social que suponía la ocupación de las mujeres de la «tribuna». El acceso femenino al espacio público era incompatible, desde su perspectiva, con la mujer doméstica, religiosa y transmisora de las costumbres en el ámbito familiar, porque las mujeres perdían honra y virtud cuando trataban de ocuparse de los comicios electorales o de la política. La ascendencia del liberalismo maurista, apoyado por los sectores católicos, y sus posiciones represivas en lo que hacía referencia a las propuestas laicistas y modernizadoras del republicanismo, son citadas por Isabel Peñarrubia, autora de la investigación, como una de las la posibles causas que impidió la celebración del Congreso Nacional Femenino ${ }^{18}$.

Por esas fechas los límites de la feminidad se acotaban por los sectores conservadores vinculados a los postulados más dogmáticos de la Iglesia católica en las fronteras de la domesticidad. Una vez recompuesto en 1882 el republicanismo federal y activos de nuevo sus núcleos de afinidad, la difusión de distintos modelos de feminidad acrecentarían las pugnas entre diferentes culturas políticas con el propósito también de extender su hegemonía sociopolítica. Para los feminismos republicanos en proceso de reconstrucción, «lo público» se revelaría como un nuevo espacio a conquistar en la progresiva consolidación de otras identidades femeninas en mayor medida transgresoras, que, paralelamente al igualitarismo educativo, abrieran a las mujeres espacios organizativos autónomos aunque vinculados a determinados partidos. Nuevos espacios en los que se prepararon para ejercer una ciudadanía activa que con el paso del tiempo les permitiría demandar un conjunto de derechos sociales y políticos entre los que sobresaldría la vindicación del sufragio.

\section{Feminismos republicanos. El largo camino hacia la política}

Las redes feministas que conformaron diversos núcleos de mujeres republicanas y librepensadoras como la Asociación General Femenina en Valencia (1897-1910); la Sociedad Progresiva de Barcelona (1898-1920), con filiales en diversos puntos de Cataluña; la Unión Femenina del Librepensamiento en Huelva (1897-1906); la Sociedad de Mujeres Librepensadoras en Mahón (1899-?) y la Sociedad Progresiva Femenina en Málaga (1900-1907) ${ }^{19}$,

18. Ibidem, pp. 221-246.

19. Véase al respecto RAmos, $M^{a}$ Dolores, «La república de las librepensadoras (1890-1914): laicismo, emancipismo, anticlericalismo», en RAMOS, $\mathrm{M}^{a}$ Dolores (ed.), República y 
difundieron significados en torno a la feminidad que incidían en defender una ética social secular y alternativa en la que en cualquier caso se abundaba en la necesidad de profundizar en la igualdad de deberes y derechos entre los sexos. Trataban asimismo de fomentar la libertad de conciencia, promover la ciencia y la instrucción laica, también la superior, entre la población femenina. Además pretendían concienciar a los hombres de que la liberación de las mujeres era necesaria para su propia liberación. El desarrollo de su acción social se centró mayoritariamente en cuatro frentes en los que desarrollaron sus actividades: escolar, periodístico, pacifista y cívico secularizador ${ }^{20}$.

Las exhaustivas investigaciones de $\mathrm{M}^{\mathrm{a}}$ Dolores Ramos ofrecen al respecto una visión pormenorizada de las iniciativas de dichos grupos femeninos que contaron con figuras tan emblemáticas en sus filas como Belén Sárraga, Ángeles López de Ayala, Rosario de Acuña o Ana y Amalia Carvia, entre otras. Dichas mujeres entrecruzaron prácticas y discursos con espiritistas, masones o librepensadores que actuaban en la órbita del republicanismo impulsando proyectos plenamente vanguardistas a través de una sociabilidad popular activa y democrática. En este sentido, cabe recordar que los movimientos sociales, en el camino de hacer consciente a la sociedad de lo injusto de su situación, a la vez que alteran las normas sociales afianzando otros modelos de identidad, suelen recabar solidaridades entre sectores afines que reconocen las nuevas identidades que se atribuyen y contribuyen a difundir sus proyectos y reivindicaciones. Es lo que los estudiosos de la acción colectiva denominan la difusión por coalición social ${ }^{21}$.

Por ello, las mujeres impulsoras del llamado feminismo laicista ${ }^{22}$ exhibieron identidades femeninas en gran medida politizadas y autónomas, manifestando con ello superar las atribuciones de género previstas para las mujeres de su tiempo. Así, ocuparon las tribunas públicas, participaron como oradoras en mítines y en otros actos promovidos en casinos, escuelas laicas y demás

republicanas en España, Ayer, no 60 (2005/4), pp. 45-74 y RAmOS, M ${ }^{a}$ Dolores, «Heterodoxias religiosas, familias espiritistas y apóstolas laicas a finales del siglo XIX: Amalia Domingo Soler, Belén de Sárraga Hernández», en SAlomón, Pilar y Moreno, Mónica (coords.), Género, religión y laicismo, Historia Social, no 53 (2005), p. 68.

20. RAMOS, $M^{a}$ Dolores, «Hermanas en creencias, hermanas de lucha. Mujeres racionalistas, cultura republicana y sociedad civil en la Restauración», en RAMOS, $\mathrm{M}^{a}$ Dolores (coord.): Laicismo, identidades y cultura politica: Mujeres fragmentadas, Arenal, $\mathrm{n}^{\circ} 2$ (julio-diciembre 2004), p. 30.

21. TARROW, Sydney, El poder en movimiento. Los movimientos sociales, la acción colectiva y la política, Madrid, 2004, pp. 85-86.

22. La denominación de «feminismo laicista» en FAGOAGA, Concha, «La herencia laicista del movimiento sufragista en España», en AGUADO, Ana (coord.), Las mujeres entre la historia y la sociedad contemporánea, Valencia, 1999, pp. 91-111. 
centros librepensadores, obreros y republicanos, actuaron como delegadas en congresos del librepensamiento de ámbito nacional e internacional, fundaron logias o participaron en «los trabajos» masónicos, abrieron escuelas laicas nocturnas y diurnas para niñas y adultas, dirigieron y editaron periódicos y publicaron en la prensa afín, participando de una forma en gran medida igualitaria en el tejido asociativo articulado en torno al republicanismo y al internacionalismo en el tránsito del XIX al XX.

Los discursos del feminismo laicista, inscritos en las ideas, principios y valores propios de la cultura política republicana, adaptaban dicha cultura a la especificidad de las mujeres proponiendo soluciones para modificar su situación de atraso y dependencia social. Belén Sárraga en un mitin organizado por los librepensadores de Sagunto afirmaba por ejemplo: «[...] que no quería esclavas ni que siguieran sus doctrinas, sino que se instruyeran y luego con libertad siguieran las doctrinas que les inspirase su libre criterio.... $\rangle^{23}$. O, también Amalia Carvia decía en El Socialista: «Si el hombre comprende la necesidad de apoyo a la mujer en la vida privada, ¿por qué no reconocer esta misma necesidad en la vida pública? $»^{24}$. En última instancia, sus actuaciones aspiraban a comprometer a los republicanos, tanto a los hombres como a las mujeres, de la necesidad de configurar e impulsar una ciudadanía femenina progresivamente en clave democrática. Complementariamente estructuraban redes femeninas que les permitieran sumar fuerzas, mantener contactos y potenciar su acción social haciendo llegar a la opinión pública las actuaciones e ideas de las mujeres más implicadas en la «dignificación del sexo femenino».

En ese mismo tiempo, en los círculos republicanos, los hombres difundían mayoritariamente modelos de feminidad que abundaban en el valor de las mujeres en el ámbito familiar. Este ideal de feminidad republicana hacía de las mujeres las garantes del mantenimiento y transmisión de la cultura republicana en la vida privada y, sobre todo, las responsabilizaba de la educación de hijos e hijas en las ideas del progreso o del laicismo. Por ello, aun cuando se promovía la necesidad de facilitar a las mujeres una mayor educación, también la superior, en la mayoría de los casos, dicha educación se hacía depender de sus competencias en el ámbito de la maternidad. Como afirmaba el diario republicano El Pueblo «el día que las mujeres fuesen ilustradas e inculcasen a sus hijos los ideales del progreso la «reacción» quedaría desarmada para siempre» ${ }^{25}$. También se esperaba que las mujeres manifestasen su republicanismo en la vida pública, acudiendo a mítines, manifestaciones y demás

23. El Pueblo, 24-IV-1899.

24. El Socialismo, quincenario anarquista, Cádiz, n 40, 15-IX-1887.

25. El Pueblo, 20-V-1897. 
actos de sociabilidad, aunque en pocos casos se discutía el dominio exclusivo de los hombres en la política «oficial» y su preeminencia en la gestión de las cuestiones del estado y del gobierno ${ }^{26}$. Además, los discursos masculinos enfatizaban exageradamente las dependencias femeninas de la religión católica y las sospechas de que los clérigos utilizaban a las mujeres para influir en la conciencia de sus esposos y trasladar ideas nocivas a la familia y a la sociedad, lo que las inhabilitaba para acceder a las tareas de gobierno y para ejercer el sufragio $^{27}$. Asimismo era patente la animadversión de los hombres hacia las damas clericales, llamadas «damas negras o fraileras» que en ciudades como Valencia y Barcelona en torno a 1909 contaban con una potente organización de auxilio y propaganda entre las obreras, convocaban mítines y asistían masivamente a las manifestaciones que promovían la Liga Católica ${ }^{28}$.

Progresivamente, feminidad y política estaban dejando de ser términos excluyentes y, por ello, en el entorno del republicanismo blasquista que podemos tomar como ejemplo se consideraba que las «damas rojas» debían hacer frente a las clericales, constituyendo asociaciones femeninas que posibilitaran a las republicanas desarrollar una acción social organizada.

Desde esta lógica y auspiciadas por el partido Unión Republicana surgió en Madrid un grupo de Damas Rojas que desde 1909 hasta 1911 desplegaron una considerable acción política y social en colaboración con la Agrupación Femenina Socialista ${ }^{29}$. Sus objetivos se cifraban en propagar entre las mujeres los ideales de Libertad y de República y también organizar comisiones de visita a las cárceles y a las familias de los presos, visitas a enfermos y heridos y propaganda radical femenina. Como afirma Marta del Moral, autora de la investigación, la Conjunción de republicanos y socialistas propiciaba la colaboración entre las mujeres de ambas tendencias que organizaron mítines especialmente dedicados a combatir el clericalismo y la guerra de Marruecos, participaron en manifestaciones y acudieron a los colegios electorales para

26. Dardé Morales, Carlos, «El movimiento republicano. Los hombres, los partidos, los programas y la práctica política», en ESPADAS BURGOS, Manuel (coord.), La época de la Restauración (1875-1902), vol. I: Estado, Política e Islas de Ultramar, t. XXXVI, Historia de España de Menéndez Pidal, Madrid, 2000, pp. 555-573.

27. A este respecto véase SALOMÓN, $M^{a}$ Pilar, «Beatas sojuzgadas por el clero: la imagen de las mujeres en el discurso anticlerical en la España del primer tercio del siglo XX», en AMADOR, Pilar (coord.) y MOREno, Mónica (ed.), Imagin/ando a la mujer, Feminismo/s, $n^{\circ} 2$ (2003), pp. 41-58.

28. Sanfeliu, Luz, Republicanas. Identidades de género en el blasquismo (1895-1910), València, 2005.

29. Del Moral Vargas, Marta, «Acción colectiva femenina republicana: Las Damas Rojas de Madrid (1909-1911), una breve experiencia política», Hispania. Revista Española de Historia, nº 226 (mayo-agosto 2007), p. 547. 
garantizar la limpieza de los comicios. De la citada organización formaron parte Consuelo Álvarez, conocida como Violeta, Aurora Martínez, Josefa Hurtado y también Carmen de Burgos, militante por esos años de la Agrupación Femenina Socialista. En 1910 las medidas «laicas» de Canalejas y la ley del Candado agravaron los antagonismos entre «damas» de distintas tendencias y, en Madrid, la propia Carmen de Burgos, conocida en ese tiempo por su defensa de derechos para las mujeres, como el derecho al divorcio o el acceso a la educación, y por mantener en la prensa y en la literatura una actitud militante en torno a la emancipación femenina, encabezó los preparativos de un mitin femenino multitudinario que se celebró en el Teatro Barbieri, en la llamada República de Lavapiés. En este acto las oradoras fueron mujeres y la mayoría de asistentes también ${ }^{30}$. Finalmente, este grupo impulsó la recogida de firmas y participó en una nutrida manifestación que recorrió Madrid y también hubo manifestaciones en Alicante, Badajoz, Gijón, Jaén, León,... ${ }^{31}$.

De forma similar, en Barcelona el activismo de las Damas Rojas, las Damas Radicales y la Sociedad Progresiva Femenina se solaparon en esos años facilitando la «doble militancia» entre las Damas Radicales y las de la Progresiva liderada por Ángeles López de Ayala. En este caso, las colaboraciones de ambos grupos se inscribían en un entramado asociativo autónomo, estable y acrisolado en el tiempo en torno a las actividades de la Progresiva que contaba con una nutrida red de centros en Barcelona y su entorno, y con publicaciones como El Gladiador del librepensamiento. La polémica ley del Candado, también en dicha ciudad, movilizó a las mujeres convocadas por las tres organizaciones a iniciativa de Ángeles López de Ayala. Ella fue la encargada de dirigir la palabra desde el balcón del gobierno civil a las más de cien mil personas asistentes a la manifestación. Asimismo, las tres asociaciones organizadoras entregaron a la primera autoridad un manifiesto firmado por veinte mil mujeres en apoyo del gobierno liberal ${ }^{32}$.

En última instancia, las diferencias entre mujeres de tendencias clericales y anticlericales consolidaron protagonismos femeninos, como los de Carmen de Burgos y Ángeles López de Ayala, ambas relacionadas en esos años con el republicanismo o el socialismo pero también con la acción social a favor de la causa de las mujeres. En este clima de oportunidad para la acción colectiva femenina se visibilizaron asimismo nuevas identidades femeninas relacionadas con la militancia de las mujeres en organizaciones vinculadas a determinados partidos políticos. Aun cuando cabe apuntar que apenas se plantearon

30. Utrera, Federico, Memorias de Colombine. La primera periodista, Madrid, 1998, p. 191.

31. Del Moral Vargas, Marta, «Acción colectiva femenina republicana...», p. 560.

32. RAMOS, $\mathrm{M}^{a}$ Dolores, «Hermanas en creencias, hermanas de lucha....», pp. 47-55. 
demandas tendentes a modificar en profundidad el sistema de relaciones de género vigente en la sociedad y las actuaciones femeninas revistieron un carácter ambivalente, en algunos casos accesorio e instrumental ${ }^{33}$.

Posteriormente las organizaciones de Damas Rojas desaparecerían del panorama militante mientras que los núcleos del feminismo laicista siguieron manteniendo su activismo. El Grupo Femenino Socialista de Madrid continuó también ampliando sus redes y actuaciones en colaboración con sociedades obreras integradas mayoritariamente por mujeres encuadradas en la UGT ${ }^{34}$. En cualquier caso, la feminidad se había dotado de un nuevo valor para las políticas en un contexto social en el que los partidos consideraban prioritario agrupar a las masas y la política empezaba a hacerse en gran medida en la calle y en los medios de comunicación.

En la ciudad de Valencia, entre 1909 y 1910, los intentos de los republicanos blasquistas para constituir una organización femenina que se contrapusiera a la de las damas clericales dieron como resultado que Amalia Carvia, María Marín y «Ella» publicaran en el Pueblo en dos secciones fijas, que durante más de un año trataban de animar a otras republicanas para a llevar a cabo este objetivo ${ }^{35}$. Los discursos de estas tres mujeres, vinculadas a los núcleos del feminismo laicistas y a la Asociación General Femenina de Valencia, se articularon en torno a dos ejes cuya novedad anticipaba los cambios que se estaban produciendo entre quienes constituían los grupos más avanzados en la reivindicación de la emancipación femenina en España. En primer lugar, los escritos femeninos-feministas seguían demandando una educación moderna y racional para que las mujeres pudieran ejercer sus funciones como madres en la familia republicana, pero también para que lograran autonomía e independencia económica ejerciendo profesiones de mayor prestigio. No obstante, la educación se difundía como una de las principales herramientas que tenían las mujeres para tomar conciencia de su subordinación y abrazar el compromiso de subvertir el orden social impuesto por los hombres. Unos hombres que, aún cuando se decían republicanos y liberales, desde el punto de vista de las articulistas, en pocos casos contribuían a fomentar la

33. Ibidem, p. 47.

34. Del Moral, Marta, «El Grupo Femenino Socialista de Madrid (1906-1914): pioneras en la acción colectiva femenina», Cuadernos de Historia Contemporánea, vol. 27 (2005), pp. 247-269.

35. Desde febrero de 1909 y hasta septiembre del mismo año se publica en El Pueblo de una forma regular la sección «Movimiento femenino», firmada tanto por María Marín como por «Ella». Entre septiembre de 1909 y febrero de 1910, María Marín inicia en solitario la serie titulada «Conferencias femeninas» y subtitulada «La mujer y su educación». 
instrucción de las mujeres y, en el ámbito familiar, era principalmente a los hijos varones a quienes se les facilitaba una educación digna. Por esas fechas, los hombres alfabetizados constituían el 47,40 de la población y las mujeres el $34,20^{36}$. Los varones blasquistas, al frente del poder municipal en la ciudad de Valencia durante casi una década, pocas iniciativas prácticas habían emprendido para facilitar a las mujeres y a las niñas una educación de calidad.

En una línea argumental similar, Amalia Carvia denunciaba también la falta de apoyo que recibía el feminismo por parte de esos mismos hombres progresistas que ante las demandas de las mujeres preocupadas por la dignificación de su sexo, mayoritariamente respondían «con la estúpida muletilla del vayan á fregar» ${ }^{37}$. Con ello, las republicanas feministas identificaban con mayor nitidez cuáles eran las causas y quiénes los causantes de las desigualdades de género. Es lo que se ha denominado la «atribución de responsabilidades» que lleva aparejada la consolidación de cualquier movimiento social ${ }^{38}$. Si en los años anteriores habían difundido la idea de que el clero, los sectores conservadores y los dogmas de la Iglesia católica eran los causantes de la subordinación de las mujeres, en torno a esas fechas, también una parte de hombres, incluidos liberales y republicanos, pasaban a ser responsables de mantener a las mujeres en el atraso y en la falta de libertad.

Por ello, y en segundo lugar, desde su perspectiva, la liberación femenina debía confiarse en mayor medida a las organizaciones femeninas autónomas que, como sucedía en los países extranjeros más avanzados, agrupaban a mujeres de distintas clases sociales y de diversas ideologías para reclamar derechos comunes que les eran negados ${ }^{39}$. Así, los artículos femeninos alentaban también a las damas católicas «no fanáticas» a unirse a la causa del feminismo para ejercer determinadas presiones sociales en partidos políticos, sindicatos y gobiernos, en aras de demandar derechos políticos y modificar las leyes del Estado. En este sentido, Celia Amorós afirma que en la construcción de una subjetividad femenina en mayor medida independiente, las mujeres precisaron contar con una poderosa voluntad de «deslealtad» hacia los preceptos impuestos por «otros» y también hacia esos «otros» que cincelaban la identidad femenina. Pero necesitaron además atreverse a inaugurar identidades capaces

36. LAZARO LORENTE, Luís M., «La educación de la mujer en la comarca de l'Horta 18601940), Ideco, no 6 (1989-1991), p. 59.

37. Amalia Carvia, «Ofrenda de agradecimiento», El Pueblo, 6-I-1909.

38. De Miguel, Ana, «El movimiento feminista y la construcción de marcos de interpretación: el caso de la violencia contra las mujeres», Revista Internacional de Sociología -RIS-, no 35, (Mayo 2003), pp. 127-150.

39. María Marín, «Las sufragistas inglesas», El Pueblo, 15-IV-1909. 
de crear pautas autorreferenciales que leyesen y organizasen la «realidad»a partir de claves elaboradas desde las propias experiencias femeninas ${ }^{40}$.

\section{El derecho al voto, paradigma de la autonomía feminista}

Como preludiaban las «Conferencias Femeninas» publicadas en El Pueblo, el minoritario feminismo laicista iba a emprender en pocos años un cambio importante en los marcos conceptuales que fundamentaban sus reclamaciones y también en las estrategias que animaban su acción social. La difusión de demandas basadas originariamente en el laicismo y en la reivindicación de la libertad de las mujeres se transformaría en posturas igualitarias y en reclamaciones abiertamente sufragistas ${ }^{41}$. Pero también, la petición del voto haría manifiesta la capacidad que estaban adquiriendo organizaciones feministas de distintas ideologías, aunque todas ellas de tendencia aconfesional, para aliarse con otras mujeres a través de redes de apoyo y reconocimiento mutuo, consolidando un movimiento social independiente, capaz de elaborar discursos y prácticas autoreferenciales, a partir de las cuales comenzar a construir una nueva cultura política feminista ${ }^{42}$ en gran medida autónoma de la autoridad masculina.

En 1910 la llegada al poder del gobierno de Canalejas había significado un intento de regeneración interna del sistema de la Restauración que supuso una cierta modernización social y política. El Partido Radical de Lerroux movilizaba entonces a buena parte de la plebe urbana que le respaldaba en las urnas en ciudades como Barcelona y Madrid. En Valencia los blasquistas gobernaban la ciudad y obtenían representación parlamentaria. La Convergencia de socialistas y republicanos había llevado a Pablo Iglesias a ser elegido el primer diputado obrero en el parlamento español. También los sectores institucionistas habían formado en 1912 un nuevo partido, el Reformista, ampliando desde la moderación el espectro de la izquierda y facilitando un proceso de apertura gradual hacia una democratización del régimen ${ }^{43}$.

40. Amóros, Celia, Hacia una crítica de la razón patriarcal, Barcelona, 1991, pp. 226-250 y «Mujer y participación política», en AstelarRA, Judith (edit.), Participación política de las mujeres, Madrid, 1990, pp. 107-131.

41. FAGOAGA, Concha, «De la libertad a la igualdad: laicistas y sufragistas», en SEGURA, Cristina y NiELFA Gloria (eds.), Entre la marginación y el desarrollo: Mujeres y hombres en la historia. Homenaje a María Carmen García-Nieto, Madrid, 1996, pp. 168-198.

42. La caracterización del feminismo como cultura política en NASH, Mary, Dones en Transició. De la resistencia a la legitimitat feminista: les dones en la Barcelona de la Transició, Barcelona, 2007.

43. El seguimiento de estas cuestiones en SUÁREZ CorTina, Manuel, La España liberal, Madrid, 2006, pp. 173-183. 
Desde la aprobación del sufragio masculino la capacidad de intervención de los hombres de los sectores populares en la política se había ido consolidando, lo que había propiciado su acceso a mayores cotas de derechos ciudadanos, en muchos casos, contando con el apoyo del republicanismo que, a su vez, había ido conquistando mayores parcelas de poder social y político.

Sin embargo, a pesar de la adhesión de las mujeres al movimiento republicano de una forma irregular pero significativa, sobre todo, en las actividades de sociabilidad, los hombres de esta tendencia continuaban considerando que las funciones de las mujeres debían centrarse en el hogar y, en todo caso, los derechos femeninos debían ampliarse en cuestiones como el acceso a la educación y a la cultura, el goce de mayor libertad sexual o en torno a demandas como la ley del divorcio o del matrimonio civil. En líneas generales, éstos eran desde la perspectiva de Blasco Ibáñez, que se declaraba contrario al feminismo, los cambios a los que debían aspirar las mujeres para superar su estado social de dependencia ${ }^{44}$. Lerroux, en la encuesta que llevó a cabo Carmen de Burgos en 1919 en el Heraldo de Madrid sobre el tema del sufragio femenino, afirmaba que éste era un derecho que no se podía negar a las mujeres, pero se mostraba dubitativo ante la posibilidad de concederles la condición de electoras y elegibles dado los riesgos que tal decisión podría comportar ${ }^{45}$. Los socialistas varones compartían discursos similares ya que prioritariamente se promovía un modelo de mujer fuerte, sacrificada y servicial, madre de numerosos hijos e hijas y con energía inagotable para trabajar por la familia ${ }^{46}$. Aun cuando algunas mujeres socialistas, en torno a 1914, ya se denominaban feministas y pedían mayor interés por parte del partido y de la prensa socialista hacia su causa ${ }^{47}$.

Desde esta perspectiva, las peticiones de «plenos derechos políticos para las mujeres», formuladas de una forma pionera por Ángeles López de Ayala en 1913 durante la celebración en Barcelona del Congreso Nacional de la Libertad $^{48}$, respondían a la lógica de manifestar cierta deslealtad hacia esos sectores masculinos contrarios a un mayor igualitarismo entre los sexos. Pero, la evolución hacia el sufragismo de López de Ayala y de la Progresiva señalaba además la necesidad de que las identidades femeninas experimentaran una

44. Blasco Ibáñez, Vicente, Discursos literarios, Valencia, 1966, pp. 337-343.

45. Utrera, Federico, Memorias de Colombine..., p. 359.

46. Llona, Miren, «Género e identidad de clase. La construcción de la clase obrera vizcaína durante el primer tercio del siglo XX», Historia Social, n 54 (2006), p. 105.

47. BizCARRONDO, Marta, «Los orígenes del feminismo socialista en España», en VV.AA., Las mujeres en la historia de España. Siglo XVI-XX, Madrid, 1984, pp. 148-150.

48. RAMOS, $\mathrm{M}^{a}$ Dolores, «Hermanas en creencias, hermanas de lucha...», p. 56. 
nueva ruptura de límites que permitiera a las mujeres acceder a una ciudadanía en mayor medida igualitaria.

A la vez que las asociaciones femeninas-feministas de republicanas y socialistas se habían organizado en conjunción tomando la calle, se habían eliminado las trabas para el ingreso de las mujeres en la Universidad, reconociéndose oficialmente que los títulos obtenidos les facultaban para el ejercicio profesional. En 1911, la creación de la Escuela Superior de Estudios del Magisterio añadía un nuevo impulso a la ya consolidada Escuela Normal Central, ya que dicha entidad se nutría de maestras que se caracterizaban no sólo por defender nuevas teorías y prácticas educativas, sino por ostentar una manera moderna de vivir que las convertía en modelos para el conjunto de las mujeres ${ }^{49}$. También la recién creada Junta de Ampliación de Estudios concedía por esos años pensiones a cientos de maestras y profesoras, en rigurosa y precoz paridad, para realizar estudios pedagógicos en el extranjero. La estrecha colaboración con la Junta permitió a María de Maeztu estudiar fuera de las fronteras españolas con la finalidad de evaluar los sistemas pedagógicos y educativos europeos. Las experiencias acumuladas la habilitaron para dirigir en 1915 la Residencia de Señoritas de la que posteriormente surgiría el Lyceum Club $^{50}$. En torno a estos círculos estaba naciendo una generación de jóvenes de clases medias urbanas que posteriormente se convertirían en profesionales independientes con una sólida formación artística, cultural e intelectual $^{51}$.

Así pues, aun cuando una parte importante de la tarea educativa de mujeres y niñas restaba pendiente en España, la propia instrucción y el acceso de las mujeres a profesiones liberales eran en menor medida cuestionables. En última instancia, se estaba configurando un nuevo modelo de feminidad, la llamada «mujer moderna», caracterizada por ser hasta cierto punto independiente y culta. Un modelo que sin embargo mantenía vigente la idea de la complementariedad entre los géneros. Una complementariedad en la que a los varones les correspondía continuar dirigiendo la esfera pública y la gestión de la política.

49. Agulló DíAz, Ma del Carmen, Mestres valencianes republicanes. Las luces de la República, València, 2008, p. 22.

50. GALLEGO, Isabel, «María de Maeztu y la tradición de la educación liberal española», en Jimenéz Tomé, Ma José y Gallego RodríGuez, Isabel (eds.), Españolas del Siglo XX promotoras de la cultura, Málaga, 2003, pp. 42-44.

51. BAROJA Y Nessi, Carmen, Recuerdos de una mujer de la Generación del 98, ed. Amparo Hurtado, Barcelona, 1998, p. 69. 
Por ello, la nueva etapa iniciada en 1913 con la reedición de El Gladiador del librepensamiento y sus campañas a favor de pacifismo y del sufragio, de algún modo, trataba también de proporcionar a esas «nuevas mujeres» que se estaban construyendo ${ }^{52}$ nuevos marcos de identificación como ciudadanas con capacidad de integrarse plenamente en la política y de gozar de plenos derechos. Con parecidas intenciones pacifistas y sufragistas, en 1915 se editó en Valencia la revista Redención y las hermanas Ana y Amalia Carvia emprendían la refundación del primitivo feminismo laicista valenciano con la constitución de la Sociedad Concepción Arenal. En el primer ejemplar de Redención, aparecía el lema «Ven mujer, ven a nosotras y laboremos juntas por nuestra CULTURA y nuestros DERECHOS». La publicación tenía por objetivo la difusión de los logros de «sus nobles hermanas de otros países», la adhesión de mayor número de mujeres al movimiento, mujeres a las que no se les iba a preguntar ni «cuáles [eran] sus ideas políticas, ni cuáles [eran] sus dogmas» y, finalmente, se proponían señalar deficiencias y plantear reformas, «desde el punto de vista feminista y humanitario», para modificar los códigos y la jurisprudencia persiguiendo la «igualdad de derechos $»^{53}$.

Ampliando el campo de su actuación, y transcurridos tres años, la Sociedad Concepción Arenal, la Sociedad Progresiva Femenina, el grupo de Redención, el grupo de El Gladiador y un total de 54 mujeres más pertenecientes a otros grupos de Madrid, Andalucía y Galicia establecieron una acciones coordinadas a través de Liga Española para el Progreso de la Mujer que, de forma pionera, envió al parlamento la petición del voto mientras se debatía de ley de los conservadores conocida como proyecto de Burgos y Mazo ${ }^{54}$.

De forma paralela las demandas sufragista eran compartidas desde 1918 por la Asociación Nacional de Mujeres Españolas (ANME) en la que militaron entre otras mujeres María Espinosa, Benita Asas, Dolores Velasco, Julia Peguero, Elisa Soriano, María de Maeztu o Clara Campoamor, cuya ideología iba desde «las ideas izquierdistas extremas» hasta «las religiosas en sumo grado $»^{55}$. Bajo la presidencia de María Espinosa de los Monteros, la ANME y la Liga Española para el Progreso de la Mujer iniciaron contactos para constituir una organización que diera mayor solidez a sus demandas. Superadas las iniciales prevenciones, en 1919 se constituyó el Consejo Supremo Feminista integrado por cinco asociaciones: la Sociedad Progresiva Femenina, la Liga

52. Esta idea en RAmOS, $M^{a}$ Dolores, «Hermanas en creencias, hermanas de lucha...», p. 56.

53. Redención, 1-IX-1915.

54. FAGOAGA, Concha, «La herencia laicista del movimiento sufragista...», pp. 106-107.

55. FAGOAGA, Concha, La voz y el voto de las mujeres..., pp. 129-130. 
Española para el Progreso de la Mujer, la ANME, la Sociedad Concepción Arenal de Valencia y la Asociación La Mujer del Porvenir de Barcelona ${ }^{56}$. De esta forma las antiguas redes informales del feminismo laicista, reorganizadas en pro del sufragio, llevaban a cabo sus propósitos de articular un movimiento feminista que trataba de recabar apoyos entre otras organizaciones feministas considerando en un segundo plano las tendencias ideológicas de quienes las integraban. Se comenzaba a constituir una identidad colectiva feminista, un «nosotras» articulado en función de los intereses específicos de las mujeres en tanto que mujeres, con capacidad de abstraerse de las diferencias que por fuerza habría de tener «un sujeto colectivo» que comprendía a la mitad de la humanidad ${ }^{57}$.

María Espinosa de los Monteros en la conferencia que impartió en la Real Academia de Jurisprudencia y Legislación en 1920, aun cuando decía hablar en representación de la ANME, manifestaba también lo trascendental del trabajo común de las asociaciones que formaban el Consejo Supremo Feminista puesto que «[...] en el fondo, todas las feministas, no de España, del mundo entero, t[enían] esa suprema aspiración de igualdad de derechos y de obligaciones en ambos sexos» ${ }^{58}$. En 1915 en Redención se difundían la inscripción de alguna de sus redactoras a La Union Mundiale de la Femme, organización de impronta feminista y pacifista fundada en Ginebra ${ }^{59}$. La Comisión Organizadora de la Liga mantenía también contacto con Hermila Galindo, directora del quincenal Mujer Moderna, publicado en México entre 1915 y 1919 ${ }^{60}$. Como afirmaba María Espinosa en su intervención, por esas fechas, el movimiento feminista transcendía las reivindicaciones locales manifestando su capacidad para intercambiar ideas y poner en marcha acciones colectivas de un creciente alcance geográfico y social.

En el amplio programa que la presidenta de la ANME presentó en la Real Academia de Jurisprudencia, se demandaban de forma pormenorizada un nutrido número de derechos sociales, civiles y políticos para la población femenina. Años más tarde, dichos derechos coincidirían en gran medida con las reformas legislativas aprobadas en la II República que hacían referencia

56. FAGOAGA, Concha, «La herencia laicista del movimiento sufragista...», p. 107.

57. VAlCARCEL, Amelia, La política de las mujeres, Madrid, 1997, p. 91.

58. ESPINOSA, María, «Influencia del feminismo en la legislación contemporánea», en MARTín-GAMERo, Amalia (Introducción y comentarios), Antología del feminismo, Madrid, 1975, pp. 193-200.

59. «La Unión de la Mujer», Redención, 1-IX-1915.

60. FAGOAGA, Concha, «La herencia laicista del movimiento sufragista...», pp. 106-107. 
específica a la igualdad entre los géneros y a los derechos políticos y civiles de las mujeres ${ }^{61}$.

A través de la revista Redención, que se publicó hasta 1923, se constata también que a lo largo del tiempo se llevaron a término los objetivos del Consejo Supremo Feminista, puesto que en sus páginas se difundieron las actuaciones de las distintas asociaciones que lo integraban, lo que en última instancia multiplicaba las posibilidades de la acción social feminista. Así Julia Peguero relataba en dicha revista el acto promovido por la ANME y que había tenido lugar en el teatro Princesa para impulsar una sólida campaña para la reinserción social de las mujeres reclusas ${ }^{62}$. Asimismo se anunciaba la fundación de la Juventud Universitaria Feminista en Madrid animando a las estudiantes de otros lugares para que se organizaran en grupos similares ${ }^{63}$.

La puesta en marcha de la Juventud Universitaria Feminista constituye una muestra más de cómo el feminismo, en muchos casos, articulaba redes amplias de solidaridad entre mujeres en pro de un objetivo común. La JUF se planteó la intención de constituirse como filial de ANME aun cuando, en una primera instancia, algunas de sus líderes y colaboradoras provenían del Lyceum Club. Para su implantación en Barcelona se contó con la colaboración de Carmen Karr, de Acción Femenina, y María de Meztu, directora de la Residencia de Señoritas, fue la encargada de conectar la JUF con la International Federation of University Women ${ }^{64}$.

\section{La ciudadanía femenina provisionalmente consolidada}

Durante los debates del texto constitucional en la Cámara en 1931, los grupos feministas siguieron presionando para que las mujeres obtuvieran el voto y se reconocieran los derechos que desde 1919 venían demandando. Era la continuación de una larga trayectoria que, si bien nunca había movilizado a las masas, sí había logrado hacer conscientes a un segmento creciente de las mujeres de clases medias de su derecho a constituirse como ciudadanas ${ }^{65}$. El consenso social en torno a dicha cuestión era compartido también por una parte de los hombres y por algunos partidos políticos.

61. Aguado, Ana, «Entre lo público y lo privado: sufragio y divorcio en la Segunda República», en RAmos, Mª Dolores (ed.), República y republicanas en España..., pp. 105-134.

62. J. P., Redención, Valencia, abril de 1920. (Las iniciales corresponden, sin duda, a Julia Peguero). La cita en FAgOAGA, Concha, La voz y el voto de las mujeres..., p. 133.

63. «La juventud Universitaria Feminista», Redención. Abril y mayo de 1920. Ibidem, p. 149.

64. Ibidem, pp. 149-154.

65. Ibidem, p. 189. 
El 30 de septiembre y el 1 de octubre de 1931, Clara Campoamor, en contra de la opinión mayoritaria de su propio partido, defendió en el debate parlamentario de las Cortes Constituyentes la aprobación del sufragio femenino basándose en el principio de igualdad como derecho universal independiente de los resultados electorales. Se consumaba así una más de las sucesivas deslealtades que las mujeres feministas habían ido perpetrando a las restricciones patriarcales. Como consecuencia de su postura Campoamor sufriría en años posteriores la marginación en su partido ${ }^{66}$. Sin embargo, los grupos que habían impulsado la consecución del voto femenino, nada más obtenerlo, celebraron en su honor distintos homenajes. En uno de estos actos celebrados en el hotel Nacional, Isabel Oyarzábal de Palencia acudía en representación del Consejo Supremo Feminista junto a otras representantes de la Cruzada de Mujeres Españolas; del Lyceum Club; de la Asociación de Mujeres Españolas; de la Federación Internacional de Mujeres Universitarias; de la Asociación Universitaria Femenina; de la Liga por la Paz y la Libertad; de la Agrupación Femenina Republicana; de Mundo Femenino; de la Asociación de Mujeres Médicas; de Mujeres Periodistas, además de representantes de la Juventud y Agrupación Socialista y de los sindicatos femeninos de la UGT y la FUE ${ }^{67}$.

Por esas mismas fechas, algunas mujeres como Amalia Carvia o Belén Sárraga, que habían comenzado al finalizar el anterior siglo su militancia en pro de la emancipación femenina, continuaban manteniéndola. Amalia Carvia era la presidenta de la agrupación «Flor de Mayo» que formaba parte de las Agrupaciones Femeninas Republicanas de Valencia vinculadas al P.U.R.A. En sus artículos en El Pueblo seguía insistiendo en que los debates entre los republicanos sobre la concesión del voto a las mujeres ya no eran sustanciales. Había llegado «la hora» de las mujeres y en ese momento sólo correspondía "ponerse al servicio de la ley y preparar a la ciudadana de forma que comprendiese lo que se iba a poner en sus manos ${ }^{68}$. A mediados de abril de 1932 varias agrupaciones femeninas celebraron un mitin en el teatro María Guerrero de Madrid para festejar el primer aniversario de la República. Entre las participantes en el acto y firmantes de la convocatoria figuraba Belén Sárraga, en representación de las Mujeres Federales. En la nota que difundió la Comisión Organizadora se señalaba que «[...] la instauración del régimen republicano ha[bía] coincidido con la más absoluta y generosa reivindicación de la personalidad política y civil de la mujer española ${ }^{69}$.

66. CAMPOAMOR, Clara, Mi pecado mortal. El voto femenino y yo, Barcelona, 1981.

67. Utrera, Federico, Memorias de Colombine..., p. 452.

68. « Sobre el voto de la mujer», El Pueblo, Amalia Carvia, 30-III-1932.

69. El Liberal, 26-IV-1932. 
En ese contexto, pese al reconocimiento político de la igualdad entre los sexos, la actividad política de las mujeres en cargos públicos, en partidos o en organizaciones políticas y sindicales era minoritaria, aun cuando miles de ellas se habían incorporado a organizaciones políticas específicamente femeninas. Se estaba haciendo posible el acceso a la vida pública de una generación de españolas que se caracterizaron por su modernidad, progresismo y preparación intelectual y que desempeñaron un importante papel político y cultural en la sociedad de su época ${ }^{70}$.

Con los nuevos y crecientes «protagonismos» de las mujeres en la vida pública y en la política estaban en vías de consolidación muchos de los principios, valores e ideas que Belén Sárraga o Amalia Carvia, entre otras muchas mujeres, habían mantenido a lo largo del tiempo con respecto a la feminidad. Unos principios y valores basados en las ideas universalistas que habían inspirado la Revolución Francesa y en una nueva tradición de pensamiento que, durante más de un lustro, había ido elaborando en España el feminismo republicano con sus diferencias de matices y sensibilidades.

70. MANGini, Shirley, Las modernas de Madrid. Las grandes intelectuales españolas de la vanguardia, Barcelona, 2000. 